\title{
EL CONTROL FINANCIERO $\left(^{*}\right)$
}

por HUGO ARANEDA DORR, Profesor Titular de Derecho Financiero, Escuela de Derecho (U. de Chile), y abogado de la Contraloría General de la República.
I.- LOS TRES SECTORES FINANCIEROS DEL ESTADO: EL SECTOR FISCAL CENTRALIZADO, EL SECTOR FISCAL DESCENTRALIZADO Y E L SECTOR MUNICIPAL.

La gestión financiera del Estado moderno ha sobrepasado los marcos tradicionales, tanto en las economías integralmente planificadas, sin empresa privada, como en aquéllas de carácter mixto en que, subsistiendo la empresa privada, coexisten con ella empresas estatales y otros entes autónomos destinados a promover el desarrollo económico y a realizar un concepto de justicia social, en el más amplio sentido de esta expresión, incluyendo no sólo la justa distribución del ingreso y la riqueza, sino también la seguridad social, a través de sistemas previsionales de carácter estatal.

A la vez, el antiguo municipio, de origen colonial en América Latina, subsiste en Chile con funciones limitadas en el orden local o comunal, encargándose de actividades tales como el ornato, aseo, la promoción cultural y el bienestar social de la comuna.

La distinta naturaleza de los fines enunciados, incorporados al campo de acción del Estado moderno, ha dado origen en Chile a tres sectores diferenciados en la gestión financiera: el sector fiscal centralizado, encargado de las funciones tradicionales, con un sistema de administración y control rígidos; el sector fiscal descentralizado, con nuevas funciones en el plano económico y social, y dotado de un sistema de administración y control flexibles; y el sector municipal, con funciones reducidas al ámbito comunal, y bajo un sistema de administración y control de carácter especial, semejante al que rige en relación con el sector fiscal descentralizado.

\section{1.- El Sector Fiscal Centraliza- do:}

Este sector cumple las funciones tradicionales: defensa exterior, orden interno, administración general, educación y obras públicas, y está sometido a un sistema de administración rígido, basado en un presupuesto aprobado por ley, que se ejecuta mediante la dictación de decretos que imputan el gasto al ítem respectivo.

Su rigidez es extrema, ya que, siendo el presupuesto aprobado por ley, sólo puede ser modificado por el mismo medio, sin perjuicio del

(*) Trabajo presentado por la Contraloría General de Chile al II Congresso Latinoamericano Je Entidades Fiscalizadoras, celebrado en Santiago de Chile, en Abrif de 1965." 
sistema de traspasos, regulado por la Ley Orgánica de Presupuestos, que, si bien modera la rigidez señalada, no constituye un recurso suficiente para adaptar la previsión presupuestaria a situaciones imprevistas.

Para estas últimas, la propia Constitución Política del Estado ha instituído el decreto de emergencia, que permita ejecutar gastos no contemplados en el presupuesto fiscal, aprobado por ley anual, hasta por un monto del $2 \%$ de los egresos globales consultados, siempre que concurran circunstancias especiales como agresión exterior, conmoción interna, calamidades públicas o agotamiento de recursos en servicios esenciales.

Además, el sector fiscal centralizado administra sus fondos a través de una sola personalidad jurídica: la del Fisco, de tal manera que cada Servicio integrado a este sector no puede ejercer derechos ni contraer obligaciones, directamente, sino por medio del Fisco, persona jurídica única, que entraba al sistema de gestión.

No obstante, considerando que el campo de acción de este sector está circunscrito al ámbito de las funciones tradicionăles, de carácter rutinario, no aparece afectado por el régimen de administración descrito precedentemente. Además, la personalidad jurídica única, concentrada en el Fisco, no afecta su. normal desenvolvimiento, por cuanto sus derechos $\mathrm{y}$ obligaciones son fundamentalmente de origen legal, y no suponen, en consecuencia, una capacidad contractual, que requiera la existencia de una personalidad jurídica separada.

Por tanto, la flexibilidad mínima, concebida más bien como una moderación de la rigidez, que deriva del sistema de traspasos y los decretos de emergencia, asegura el normal funcionamiento del sector fiscal centralizado, en el ejercicio de las funciones que le están asignadas.

\section{2.- El Sector Fiscal Descentrali- zado :}

El sector fiscal descentralizado está sujeto a un régimen de administración ágil, concordante con la amplia iniciativa que exige el cumplimiento de sus funciones en el plano económico y social. Este régimen se basa en un presupuesto flexible, aprobado por decreto supremo, y en la atribución de nersonalidad jurídica propia a cada ente, a fin de permitirle, directamente, ejercer derechos y contraer obligaciones.

Frente a circunstancias imprevistas, o ejerciendo las iniciativas inherentes : a su acción económica social, los entes autónomos que integran el sector fiscal descentralizado, modifican sus presupuestos por simple decreto, de tramitación mucho más rápida que la requerida para la modificación del presupuesto fiscal, aprobado por ley; $y$, además, pueden recurrir al sistema de traspasos por resolución del Jefe Superior del Servicio, con una amplitud mucho mayor que el sector fiscal centralizado.

Al mismo tiempo, como las funciones de este sector suponen amplia iniciativa, no pueden ser previamente determinados por la ley todos los derechos $\mathrm{y}$ obligaciones de cada ente autónomo, como ocurre en el sector fiscal centralizado, sino que la norma legal se limita a señalar sus fines, en sentido amplio, 
y dentro de ellos le permite ejercer derechos y contraer obligaciones, en virtud de la capacidad derivada de su personalidad jurídica.

Este régimen de administración, de gran flexibilidad, armoniza plenamente con los objetivos perseguidos, y facilita el ejercicio de la iniciativa que requieren las funciones de este sector, orientadas hacia fines de carácter económico y social, incluyendo la promoción del desarrollo económico, la producción directa por medio de empresas estatales, la justicia social, mediante la más justa distribución del ingreso y la riqueza, y la seguridad o previsión social, organizada por el Estado.

\section{3.- El Sector Municipal :}

El sector municipal, circunscrito a la administración local o comunal, se asemeja al sector fiscal descentralizado, tanto en la flexibilidad de su presupuesto como en la existencia de personalidad jurídica propia, en cada municipalidad separadamente.

Los presupuestos municipales son aprobados por el Intendente de la Provincia a la cual pertenece la comuna en que ejerce sus funciones la respectiva municipalidad, y pueden ser modificados en la misma forma.

A la vez, dotadas de personalidad jurídica, las municipalidades pueden ejercer derechos y contraer obligaciones, dentro de los fines que les son propios, con la capacidad contractual amplia, ya señalada al analizar la situación del sector fiscal descentralizado.

II.-EL SISTEMA DE CONTROL

\section{DE LOS TRES SECTORES FI- NANCIEROS.}

Siendo distintos los regímenes de administración financiera del sector fiscal centralizado, del sector fiscal descentralizado y del sector municipal, el sistema de control debe, por su parte, armonizar con las características propias de los sectores señalados, adaptándose a sus modalidades específicas.

Existe una relación directa entre la naturaleza del fin, que puede dar origen a funciones rutinarias o de iniciativa, y el sistema de administración, que puede ser concentrado y rígido, como el del sector fiscal centralizado, o autónomo y flexible, como el de los sectores fiscal descentralizado y municipal.

Pero esta relación se proyecta también al sistema de control, que debe adaptarse a la mayor o menor agilidad de la administración, para no entorpecer el cumplimiento de los fines del Estado.

En este orden de consideraciones, es distinto el sistema de control aplicable a cada uno de los sectores antes mencionados, según el régimen de administración a que esté sometido.

\section{1.- El Control Financiero del} Sector Fiscal Centralizado.

El sector mencionado administra sus recursos mediante un presupuesto anual, aprobado por ley, en conformidad con las disposiciones de la propia Constitución Política del Estado.

Sobre la base de la ley anual de presupuesto, se dictan decretos de fondos, que ponen recursos a disposición de los Servicios y organismos 
públicos; y decretos de pago, que ordenan gastos. La Contraloría General de la República, ejerciendo facultades constitucionales, revisa la legalidad y constitucionalidad de esos decretos, en forma previa, a través del trámite de toma de razón, y cursa los egresos que se ajusten a las normas vigentes, devolviendo sin tramitar los que las contravengan.

Existe, en este sentido, un ordenamiento jerárquico de normas jurídicas, fundado en el precepto constitucional, que dispone aprobar por ley el presupuesto fiscal, y que, sobre la base de la ley anual de presupuesto, exige la dictación de decretos de fondos y de pago, de los que debe tomar razón la Contralo: ría General, en ejercicio de sus atribuciones fiscalizadoras, antes de que se efectúe el gasto.

En la misma forma, el Organismo Contralor se pronuncia, mediante el trámite de toma de razón, sobre la juridicidad de los decretos que dispongan traspasos dentro del presupuesto fiscal, en las condiciones previstas por la Ley Orgánica de Presupuestos.

También corresponde a la entidad Fiscalizadora revisar, a través del trámite de toma de razón, los decretos de emergencia, que por un monto no superior al $2 \%$ de los gastos globales contemplados en el presupuesto vigente, permiten efectuar egresos no previstos, en situaciones especiales como agresión exterior, conmoción interna, calamidades públicas y agotamiento de fondos en servicios que no puedan paralizarse sin grave daño para el país.

Además, cuando el pago no se efectúe directamente a un acreedor del Estado, sino que se ponen fondos a disposición de un funcionario para determinados fines, mediante un decreto imputado al presupuesto, el control se prolonga hasta que el empleado rinda cuenta documentada de los fondos recibidos. Sobre esta cuenta se pronuncia el Departamento de Inspección y Examen de Cuentas, que la aprueba o repara. Si formula reparos, se inicia el juicio de cuentas, que falla en primera instancia, con los descargos del afectado, el Subcontralor, y en segunda el Contralor General.

El sistema descrito, en el ámbito concreto del control financiero, permite efectuar el gasto correspondiente, no obstante la oposición del Organismo Contralor, y reemplaza la fiscalización administrativa por el control político, de carácter más amplio, puesto que también considera razones de conveniencia $u$ oportunidad, no apreciadas en la revisión jurídica del control administrativo, basada estrictamente en las disposiciones legales o constitucionales.

Finalmente, al término de la gestión presupuestaria, corresponde a la Entidad Fiscalizadora elaborar el balance general de la Nación, acompañado de un inventario, en el que se consignan los bienes durables in: corporados al patrimonio del Estado, que han dado origen a gastos en el curso del año presupuestario. Este balance, si bien no constituye, esencialmente, un midio de control, sino una exposición del resultado final de la gestión financiera, permite confrontar la previsión presupues: taria con la ejecución del presupuesto, $y$, además, a través del inventario, hace posible la fiscalización de los bienes durables adquiridos por el Estado; que subsisten 
más allá del ejercicio correspondiente.

En general, el control financiero del sector fiscal centralizado, ejercido por la Contraloría General de la República, se adapta al régimen de administración del sector referido, y no entorpece su gestión. El trámite de toma de razón, como medio de control previo, debe ejercerse en un plazo máximo de 30 días, el que puede ser reducido hasta 15 días, cuando el Poder Ejecutivo requiere tramitación de urgencia.

Además, este sistema de control no puede amenazar los fines que el Estado persigue a través del gasto público, por cuanto se contempla el decreto de emergencia, ya analizado No obstante, sería posible agilizar, en mayor medida, el sistema de control del sector fiscal centralizado, suprimiendo los decretos de pago, cuando el gasto ya ha sido imputado al presupuesto mediante un decreto de fondos.

En efecto, en el sistema presupuestario derivadó de la actual Ley Orgánica de Presupuestos, se consultan los decretos de fondos, que ponen recursos periódicamente a disposición de los Servicios, y los decretos de pago, que efectúan el gasto directo, can cargo a los decretos de fondos.

Bastaría tomar razón de los decretos de fondos, que, al poner recursos a disposición "de los Servicios, señalan el objeto del gasto y lo imputan a un determinado ítem del presupuesto. No es esencial un segundo decreto, ahora de pago, imputado al decreto de fondos, que también esté sujeto al trámite de toma de razón.

Además, los decretos de fondos se basan en planes anuales y trimestrales para la ejecución del presupuesto, de tal manera que entregan recursos a los Servicios para fines concretos y con la imputación debida. Luego, bastaría que sobre su base, los Jefes Superiores de Servicios gastaran por simple resolución, dispensada del trámite de toma de razón, y, posteriormente, rindieran cuenta ante la Contraloría General, no ya para confrontar el decreto o resolución con la glosa del ítem respectivo, sino para comprobar que los recursos, anteriormente imputados por el decreto de fondos, se han gastado realmente en los fines que éste señaló.

Por el procedimiento analizado, sin afectar la eficiencia del control financiero, se podría dar mayor agilidad a la gestión y se evitaría la dictación de decretos innecesarios. Además, las resoluciones : que efectúen el gasto, basadas en el decreto de fondos, no se controlarían en forma previa, por la toma de razón, sino, con posterioridad por la rendición de cuentas, con las ventajas propias de una mayor rapidez en la gestión y una simplificación en el procedimiento de control.

\section{2.- El Control Financiero del} Sector Fiscal Descentralizado.

a) Integración del Sector.

El sector fiscal descentralizado surgió, precisamente, como un medio de dar agilidad a la gestión financiera, permitiendo al Estado, a través de entes autónomos, asumir con eficiencia nuevas tareas en el plano éconómico y social.

Los entes autónomos, en especial; las empresas estatales, actúan muchas veces en competencia con las 
empresas privadas, en el sistema de economía mixta que existe en Chile. Luego, si una gestión financiera rígida impidiera la iniciativa, la empresa estatal estaría condenada al fracaso, frente a una empresa privada más ágil y ejecutiva. Lo mismo ocurriría si el régimen de control frenara la acción. Por esta causa, en la situación chilena, tanto el sistema de administración como el de control para el sector fiscal descentralizado operan con la agilidad requerida para el eficiente cumplimiento de los fines económicos y sociales que el Estado persigue a través del sector mencionado, integrado por entes autónomos, con personalidad jurídica y patrimonio propio.

En Chile, para el análisis del control financiero, los entes autónomos que integran el sector fiscal descentralizado pueden dividirse en tres grandes grupos: las instituciones fiscales autónomas, las instituciones semifiscales y las empresas estataleś.

$\mathrm{Si}$ bien son similares los regímenes de administración de todos los entes autónomos, existen para ellos campos de acción claramente delimitados, cuya naturaleza esencial es necesario tener en cuenta para los efectos del control financiero.

Las instituciones fiscales autónomas actúan en la promoción del desarrollo económico, ya sea en forma general, como la Corporación de Fomento de la Producción, o en rubros especiales, como la Corporación de la Reforma Agraria y la Corporación de la Vivienda; en la educación superior, como la Universidad de Chile y la Universidad Técnica del Estado; y en la protección de la salud, como el Servicio Nacional de Salud.

En general, las instituciones fis- cales autónomas se financian, fundamentalmente, con recursos trans. feridos desde el presupuesto fiscal, que administran en ejercicio de su propia personalidad jurídica y a través de un presupuesto interno, independiente del presupuesto fiscal, aprobado normalmente por decreto supremo.

Sus recursos propios son escasos, por cuanto proporcionan servicios en forma gratuita o a precios inferiores al costo, denominados tasas, que le impiden financiarse a sí mismos, debiendo, en consecuencia, ser sostenidos por transferencias o aportes masivos desde el presupuesto fiscal.

La razón del establecimiento de estas instituciones fiscales autónomas, separadas del sector centralizado, obedece a la necesidad de agilizar su administración, para hacer posible la iniciativa creadora en el cumplimiento de sus fines. No era apropiado el sistema de administra. ción rígida del sector fiscal centralizado, por las condiciones especia. les que los referidos fines imponían a la gestión financiera.

En cambio, las instituciones semifiscales, que corresponden a las entidades de previsión principalmente, ejercen su acción en un campo diferente: el de la seguridad social, de carácter general y obligatorio, bajo la tuición del Estado; pero $f_{i}$ nanciada mediante cotizaciones previsionales, tanto de empleadores y patrones como de empleados y obreros.

Estos organismos, a diferencia de las instituciones fiscales autónomas. disponen principalmente de recursos propios, integrados por las cotizaciones previsionales a que se ha hecho referencia. No obstante, tam- 
bién reciben, aunque en menor grado, aportes o transferencias de fondos desde el presupuesto fiscal, para cubrir sus déficits frente a los beneficios previsionales que otorgan $o$, para reajustar las pensiones, cercenadas por el proceso inflacionario que ha persistido durante largo tiempo en la economía nacional.

Las instituciones semifiscales surgieron en el momento en que el Es: tado estableció un régimen de seguridad social, primero restringido a determinados grupos de trabajadores, y ahora extendido a todos los empleados y obreros, sin excepciones, e, incluso, a las profesiones y oficios independientes. En Chile coexisten diversos regímenes previsionales, por sectores, y numerosas entidades de previsión, que si bien no se apartan de la filosofía general de la previsión social chilena, dificultan el control jurídico por la heterogeneidad de la legislación que las rige.

Todas las instituciones semifiscales se administran, en el plano financiero, mediante presupuestos separados, aprobados por decretos supremo, y están dotadas de personalidad jurídica propia, lo que les asegura una amplia capacidad contractual para el cumplimiento de sus fines.

Finalmente, en el sector fiscal descentralizado aparecen las empresas estatales, que constituyen la expresión más concreta de la acción del Estado en el campo económico, antiguamente reservado, en forma privativa, a la empresa privada. La existencia en Chile de numerosas empresas estatales, unida a la regulación de la economía por el Estado y la vigencia de un programa decenal de desarrollo económico; permite sostener que impera en el país un régimen de economía mixta, en que coexisten las empresas privadas y las estatales, predominando las primeras, solamente complementadas por las segundas en la etapa actual.

Las empresas estatales, con mayor razón que las instituciones fiscales autónomas y las instituciones semifiscales, exigen una gestión extremadamente ágil, con plena iniciativa creadora y gran sentidp rjecutivo, ya que no sólo actúan en un campo esencialmente activo, como el de la economía, sino que, además, muchas veces compiten con las empresas privadas, con fines de regulación económica.

Dentro de las empresas estatales, existen las empresas fiscales, como la de Ferrocarriles del Estado, de Transportes Colectivos del Estado, Marítima del Estadó, Línea Aérea Nacional, Banco del Estado y Empresa Nacional del Petróleo, por ejemplo, y las empresas de economía mixta, en las que, bajo la forma orgánica de sociedades anónimas; concurren, en conjunto, capitales del Estado y de los particulares, como ocurre en la Empresa Nacional de Electricidad y en la Compañía de Acero del Pacífico.

Esta subdivisión de las empresas estatales, en empresas fiscales y de economía mixta, tiene gran trascendencia para los fines del control financiero. Las empresas fiscales están dotadas de personalidad jurídica propia y se administran mediante un presupuesto aprobado por decreto supremo. Además, están sujetas a la fiscalización financiera de la Contraloría General de la República; con excepción del Banco del Estado, fiscalizado por la Superintendencia de Bancos. En cambio, las empresas de economía mixta, que son jurídicamente soçiedades anó- 
nimas con participación estatal, se administran según sus propios estatutos sociales, $y$ no están sometidas al contröl financiero de la Contraloría General, sino a la fiscalización común que sobre las sociedades anónimas ejerce la Superintendencia de Compañías de Seguros, Sociedádes Anónimas y Bolsas de Comercio.

b) Formas de Control.

En general, el control financiero que incumbe a la Contraloría General de la República sobre el sector fiscal descentralizado, se ejerce principalmente mediante el trámite de toma de razón a que están sujetos los decretos supremos que aprueban los presupuestos de los entes autónomos, y las resoluciones de los Jefes de Servicios que disponen gastos o traspasos de fondos en el presupuesto vigente.

Además, en conformidad con la Ley Orgánica de Presupuestos: los entes autónomos están obligados a remitir un balace seneral al Organismo de Control, a fin de confrontar la previsión presupuestaria con el resultado final de la gestión $\mathrm{y}$, durante el ejercicio presupuestario. se mantienen destacados, en forma permanente, auditores de la Contraloría General en las diversas entidades autónomas.

El sistema de control para el sector fiscal descentralizado, bosquejado en sus líneas generales, resulta eficiente $y$, si bien podría adquirir mayor agilidad, según se explicará posteriormente, no entorpece la gestión ni impide la oportuna adopción de iniciativas.

En la primera fase, mediante el trámite de toma de razón del decreto supremo que aprueba el presu- puesto del ente autónomo, se controla que los gastos contemplados coincidan con los fines que lás Leyes Orgánicas respectivas asignan a cada institución, y que los ingresos se ajusten a los recursos afectados al funcionamiento de los organismos correspondientes. En esta forma, en el instante de iniciar su gestión, el ente autónomo recibe una confirmación de la legalidad del ejercicio previsto, tanto en lo relativo a gastos como a ingresos, y queda en condiciones de operar según la previsión presupuestaria.

Si esta previsión debe ser alterada en el curso del ejercicio, basta la modificación por decreto supremo o el traspaso por simple resolución del Jefe del Servicio, en la forma prevista por la Ley Orgánica de Presupuestos.

Tanto la resolución que dispone el traspaso como el decreto supremo que ordena la modificación, son revisados por la Contraloría General en el trámite de toma de razón, analizando su legalidad formal, en relación con el regimen presupuestario mismo, y su legalidad de fondo, en lo relativo a los fines del gasto en concordancia con los objetivos que la respectiva Ley Orgánica asigna al ente autónomo correspondiente.

También están sujctas al trámite de toma de razón y se revisan de igual manera, las resoluciones de los Jefes de Servicios que dispongan gastos imputables al presupuesto aprobado.

A la vez, con posterioridad al cierre del ejercicio presupuestario, se analiza el balance final, elaborado por el ente autónomo, confrontado la previsión y el resultado, y durante el ejercicio mismo, se mantienen 
auditores de la Contraloría General en el ente fiscalizado, para que asesoren en materia de control financiero y comuniquen al Organismo Contralor toda duda suscitada en la gestión o todo acto que pudiera revestir caracteres de ilegalidad.

En esta forma, el control del sector fiscal descentralizado opera tanto antes de iniciar la gestiớn financiera, mediante la revisión del presupuesto que la prevee, como durante la gestión misma, ya sea por medio de la toma de razón de las resoluciones de pago como por la acción de los auditores destacados, y al término de la gestión, mediante la confrontación del presupuesto - previsión-con el balance generalresultado.

\section{c) Posibles Innovaciones.}

Si bien el sistema bosquejado es eficiente y obedece a una concepción técnica adecuada, sería susceptible de ser perfeccionado, para dar mayor agilidad a la administración financiera de los entes autónomos, sin afectar la fiscalización misma.

En este aspecto, la innovación fundamental radica en limitar o suprimir, según el caso, las resoluciones que ordenen gastos con cargo al presupuesto, ya aprobado por decreto supremo y revisado por el Organismo Contralor, en el acto de la toma de razón del referido decreto.

A la vez, la innovación debe adaptarse a condiciones diferenciales, anteriormente analizadas de las instituciones fiscales autónomas, las instituciones semifiscales y las empresas estatales.

En relación con las primeras, por su gran semejanza con los Servicios Públicos del sector fiscal centraliza- do, podría aplicarse un sistema como el propuesto para el mencionado sector. Es decir, cada ente autónomo, sobre la base de un programa anual y de programas trimestrales para la ejecución del presupuesto, dictaría resoluciones de fondos, sujetas al trámite de toma de razón e imputadas al presupuesto, con indicación precisa de los gastos previstos. $Y$, fundado en las resoluciones de fondos, gastaría los recursos correspondientes en los fines señalados, sin necesidad de resolución, pero con la obligación de rendir cuenta al termino del trimestre.

En esta forma se combinaría, armónicamente, el control previo y el posterior, reforzados por la fiscalización permanente de los auditores destacados. Al mismo tiempo, se descargaría al Organismo de Control de un trabajo voluminoso, que le resta tiempo y eficacia para una físcalización más perfecta en los aspectos fundamentales.

Con relación a las instituciones semifiscales, podría adoptarse, en general, el mismo procedimiento, pero con modalidades especiales. En estas instituciones existen dos grandes rubros de gastos: los de administración y los destinados al otorgamiento de los beneficios previsionales, derivados del régimen de previsión social.

Con respecto a los gastos administrativos, basta aplicar el mismo sistema propuesto para las instituciones fiscales autónomas, ya que se trata de rubros semejantes, tanto por su națuraleza como por sus características. Pero en lo relativo a gastos destinados al pago de beneficios previsionales, se imponen modalidades específicas.

Sin duda, para un control eficiente, parece esencial una simplicación 
y unificación de los múltiples y variados sistemas previsionales vigentes. No obstante esto importaría una reforma previsional. que excede de los ámbitos y fines del simple control financiero.

Por consiguiente, partiendo de la situación existente en materia de previsión social, la agilización del control debería intentarse limitando los decretos y resoluciones al trámite de toma de razón.

En general, sólo deberían sujetarse al trámite mencionado, que supone la aplicación de un sistema de control previo, los decretos y resoluciones que reconocieran nuevos beneficios, excluyendo los destinados, simplemente, al reajuste de beneficios preexistentes. Estos últimos se fiscalizarían con posterioridad a la ejecución del gasto, mediante el balance anual, las rendiciones de cuentas periódicas y la acciớn permanente de auditores destacados en la respectiva entidad.

En el régimen previsional chileno, por efecto de un persistente proceso inflacionario, los beneficios previsionales, principalmente, pensiones de jubilación y montepío, están sujetas a reajustes ordinarios y a reajustes permanentes. Los primeros se otorgan accidentalmente, sin un régimen estable, por las leyes sobre aumentos. Los segundos, en cambio, obedecen a un régimen orgánico estable, y se pagan en forma permanente y prevista, ya sea según el alza del costo de la vida o el aumento de las rentas del cargo similar, es decir, de aquel empleo en que el pensionado cesó en funciones.

Muchas leyes de aumentos, tanto ordinarias como permanentes, han dispuesto, en forma expresa, que los reajustes se paguen sin necesidad de decreto o resolución. Se trata, en consecuencia de extender esta norma, en sentido general y permanente, de manera que no se requiera esa formalidad para el incremento de un beneficio previsional preexistente.

No obstante, el sistema de reajuste permanente basado, no en el alza del costo de la vida directamente, sino en el aumento de las remuneraciones del cargo similar, exige la asimilación del empleo en que jubiló el beneficiario a otro cargo existente, cuando aquél ha sido suprimido, la que debería ser dispuesta por resolución o decreto sujeto al trámite de toma de razón. por cuanto supone determinar la equivalencia de empleos y constituye un procedimiento básico para el ejercicio del derecho.

Finalmente, en relación con las empresas estatales, excluyendo las de economía mixta no sujetas a la fiscalización de esta Contraloría General. el sistema de control vigente resulta adecuado $y$ no requiere innovaciones fundamentales.

La gestión financiera de estás empresas debe sujetarse, como se establece en la Ley Orgánica de Presupuestos, a una previsión presupuestaria, aprobada por decreto supremo, y a un balance final, en la misma forma de los restantes entes autónomos.

No se exige resolución para los gastos que se ejecuten con cargo al presupuesto aprobado, durante el período comprendido entre la revisión previa de la legalidad de éste y su confrontación final con el balance general, que la empresa está obligada a remitir a la Contraloría General, por disposición de la Ley Orgánica de Presupuestos.

En este período intermedio de la 
gestión financiera el control permanente se ejerce por auditores destacados, que revisan la documentación de la empresa correspondiente y comunican al Organismo de Control cualquiera irregularidad en su gestión financiera.

Por último, como medida común en el régimen de control de todos los entes autónomos, sería útil establecer la facultad del Organismo de Control para permitir a las entidades sujetas a fiscalización gastar en los tres primeros meses del año presupuestario, sumas no superiores a un duodécimo por mes del total de los egresos previstos en el presupuesto, cuando la tramitación de éste, por causas excepcionales, sufriera retraso. En esta forma, existiría una medida de emergencia para hacer posible la iniciaciớn oportuna de la gestión financiera, sin presupues. tó aprobado, en caso de excepción, a fin de no entorpecer la administración con motivo del control previo que importa la revisión del documento presupuestario, en el acto de la toma de razớn del decreto que lo aprueba.

\section{3.-El Control Financiero del Sec- tor Municipal.}

En general, el sector municipal, que ejerce la administración comunal o local, se asemeja en su régimen financiero a los entes autónomos del sector fiscal descentralizados, ya que las municipalidades tienen personalidad jurídica propia $y$ patrimonio separado, que administran en conformidad con sus respectivos presupuestos.

En Chile, la autonomía financiera de las municipalidades no comprende la soberanía tributaria. Es decir, los municipios no pueden establecer impuestos, los que, en virtud del ré- gimen constitucional vigente, únicamente pueden tener su origen en la ley. No obstante, para resguardar la autonomía financiera, la ley asigna a las municipalidades ingresos propios, especialmente, impuestos afectados a su financiamiento.

Los fines de las municipalidades son limitados, y, salvo excepciones, disponen de recursos reducidos. La concentración técnica, en su incidencia en el funcionamiento de los Servicios Públicos, ha impedido a las municipalidades, circunscritas al ámbito local, sostener servicios especializados, de altos costos y rendimiento en gran escala, como los de educación, salud, pavimentación de calles y caminos, y otros que requieren ser proyectados en el ámbito nacional, o exigen inversiones cuantiosas, más allá de las posibilidades de los municipios.

En general, los fines básicos de las municipalidades corresponden al aseo. ornato, promoción cultural y bienestar social en la comuna, incluyendo alumbrado público y obras de adelanto y urbanización, para cuvo efecto emplean los fondos que la ley les asigna.

Las Municipalidades administran sus recursos mediante el presupuesto municipal, aprobado por resolución del respectivo Intendente para todos los municipios que correspondan a la provincia de su jurisdicción. Pero esta resolución aprobatoria no está actualmente sujeta al trámite de toma de razón, de manera que la Contraloría General no se pronuncia, en forma previa, sobre la legalidad de previsión presupuestaria. En cambio, revisa las rendiciones de cuenta de las municipalidades, por mensualidades, objetando los gastos que no se ajusten a las normas vigentes o que no aparezcan debidamente acreditados. 
El régimen administrativo de las municipalidades no difiere fundamentalmente del de los entes autónomos, con los que se asemeja en tres aspectos básicos: personalidad jurídica separada, patrimonio propio y presupuesto independiente del presupuesto fiscal.

Por esta causa, podría aplicarse a las municipalidades el esquema general de control financiero de los entes autónomos, con modalidades. Para este efecto, bastaría tomar razón de la resolución del Intendente de la provincia correspondiente que aprueba el presupuesto municipal, revisar el balance final, al término del ejercicio, y recibir rendiciones de cuentas trimestrales. : Además, sin mantener auditores destacados en forma permanente, como en los entes autónomos, podrían destinarse Inspectores Visitadores que, con una frecuencia conveniente, revisen la gestión financiera de las municipalidades.

En la forma señalada, la revisión del presupuesto, en el acto de la toma de razón de la resolución del Intendente que lo aprueba, permitiría fiscalizar su jurisdicidad, es decir, la adecuación de los gastos a los fines que la ley asigna a las municipalidades y la concordancia de los ingresos con los que legalmente correspondan a los municipios.

La presentación del balance final haría posible confrơntar la previsión presupuestaria con su ejecución, al término del ejercicio; y las rendiciones de cuentas trimestrales servirían para asegurar un control períodico de la gestión financiera, conjuntamente con las visitas de los Inspectores, encargados de la fiscalización de las municipalidades.

Finalmente, como un medio de seguridad para no entorpecer la ges- tión financiera en caso de retraso en la tramitación del presupuestó, debería establecerse, igual que para los entes autónomos, la facultad de la Contraloría General para autorizar gastos por duodécimos antes de la aprobación del presupuesto, durante los tres primeros meses del año.

\section{III.-LOS PRESUPUESTOS-PRO' GRAMAS Y EL CONTROL POR EL RESULTADO.}

\section{1. - Forma en que Chile ha acogi-} do la Recomendación III, 2, del Tercer Congreso de Entidades Fiscalizadoras, de Río de Janeiro.

La Recomendación III, 2, del Tercer Congreso de Entidades Fiscalizadoras, efectuado en Río de Janeiro, señaló la conveniencia de adoptảr un presupuesto funcional o presupuesto-programa que, orientado en relación con los fines del Estado, permita determinar su costo y la medida en que son cumplidos, a través del empleo de los recursos financieros.

A la vez, cơntempló la necesidad de estudiar y poner en ejecución un sistema que haga posible, no simplemente controlar el gasto de los recursos, sino también verificar el costo y rendimiento de los Servicios Públicos.

La referida recomendación acoge las nuevas tendencias presupuestarias y los actuales sistemas de control por el resultado, aplicados en los Estados modernos como consecuencia del rol activo que han asumido en el campo económico y social. El Estado actual, tanto en las economías estatales, sin empresa privada, como en las economías mixtas, en que coexisten empresas estatales y privadas, en diferentes pro- 
porciones, ha programado o planificado el proceso económico y ha ejecutado ,directamente, mediante organismos públicos, determinados fines económicos y sociales, creando para este efecto los entes autónomos a que se ha hecho referencia en los capítulos precedentes.

Los Estados que cuentan con planes o programas de regulación de la economía o del desarrollo económico, como ocurre en el caso de Chile, han debido prever la necesidad de un nuevo cuadro presupuestario, que permita orientar los recursos financieros en función de los objetivos programados, precisando el costo de cada fin y la proporción de los medios empleados en su realización.

En este aspecto, la Ley Orgánica de Presupuestos ha adoptado dos medidas fundamentales: separar el presupuesto corriente del presupuesto de capital o inversión y prever la clasificación de los gastos por programas o en otra forma que la técnica aconseje.

La separación del presupuesto corriente y de capital, en un mismo documento presupuestario, junto con mantener el principio de unidad, permite determinar el monto de los gastos destinados a la administración del Estado y el de los egresos constitutivos de inversión pública. En esta forma, es posible verificar cuánto gasta el Estado en su propia administración y cuánto invierte, incrementando el capital de la colectividad ,a través de egreso público.

A la vez, en el presupuesto corriente, que corresponde a gastos de administración, se separan los gastos de operación, con que el Estado atiende al funcionamiento de los Servicios Públicos, y los gastos de transferencia, representados por simples aportes fiscales a personas naturales o jurídicas, que persiguen fines protegidos por el Estado y subvencionados por este, como es el caso, principalmente, de la educación particular en Chile.

Por su parte, el presupuesto de capital separa los egresos en tres rubros fundamentales: inversión real, inversión financiera y transferencia de capital.

La inversión real corresponde a los gastos en la formación del capital y en la adquisición de activos físicos existentes. Es decir, está representada por gastos directos en bienes de producción, destinados a promover el desarrollo económico del país ,y en la práctica se orienta hacia inversiones sociales básicas, como puentes, caminos, puertos, fuentes de energía, obras de regadío, etc. La inversión financiera, en cambio, corresponde a gastos destinados a la compra de valores mobiliarios y la concesión de préstamos. Y là transferencia de capital está constituída, fundamentalmente, por los aportes que el Estado otorga con fines de inversión a los entes autónomos, aportes que se destinan, normalmente, a la formación del capital de las empresas estatales.

Esta clasificación de por sí constituye ya una orientación del gasto en función de los fines, por cuanto muestra objetivamente. a través de la ordenación presupuestaria, lo que el Estado gasta en administración y en inversión, y la forma como invierte, ya sea directamente en bienes físicos, indirectamente en valores mobiliarios y préstamos, o por intermedio de entes autónomos, a los cuales transfiere recursos para la formación de capital.

Además, la clasificación señalada, para facilitar el control, se encuen- 
tra complementada por la división de los gastos en partidas, que corresponden a los Poderes Públicos y a los Ministerios; en Capítulos, representativos de los Servicios Públicos dependientes de los diversos Ministerios; y en ítem que expresan, mediante una glosa, el motivo significativo del gasto.

Pero esta clasificación básica, instituída directamente por la Ley Orgánica de Presupuestos, no obsta a que se adopten otras, ya sea por programas o en la forma que la técnica aconseje, como expresamente lo ha previsto la referida ley.

En virtud de esta autorizaciớn podría establecerse en Chile un presupuesto programa o presupuesto funcional, que dividiera el gasto según las funciones básicas del Estado, lo subdividiera en sub-funciones, dentro de cada función, y en actividades específicas, en el interior de las subfunciones, para terminar con programas y proyectos concretos. expresados en costos directos.

Esta clasificación por fines, desglosada des,de la función básica hasta el objeto final y concreto, armonizaría plenamente con la acción planificada que el Estado ha adoptado en el cumplimiento de sus fi. nes, al elaborar un programa decenal de desarrollo económico, aprobado por el Comité Especial de la Alianza para el Progreso.

Al mismo tiempo, no sólo indicaría la medida en que el Estado cumple los fines previstos y destina recursos financieros a su ejecución, sino, en forma muy especial, haría posible la determinación directa del costo de cada fin y de cada uno de los proyectos o programas, a través de cuya ejecución ha sido cumplido.

Esta última posibilidad abriría paso al sistema de control por el resultado o rendimiento que si bien no corresponde a un control específicamente financiero, representa una fiscalización sobre la eficiencia de la organización estatal para el cumplimiento de sus objetivos.

En efecto, un alto costo por proyecto o programa, que sobrepase el racionalmente aceptable, determinado técnicamente, mostraría de inmediato las deficiencias de la organización estatal y señalaría la necesidad de una racionalización, para incrementar la eficiencia de los Servicios Públicos.

\section{El Control Financiero frente al Presupuesto - Programa.}

En el régimen financiero de Chile, la clasificación de los gastos por programas; en función del fin. está prevista sin perjuicio de la clasificación básica, establecida directamente por la Ley Orgánica de Présupuestos, que se ha analizado en el número precedente.

Esta clasificación básica armoniza, en justo equilibrio, el ordenamiento administrativo, por partidas (Poderes Públicos y Ministerios), Capítulos (Servicios dependientes de cada Ministerio) e ítem (motivo explicativo del gasto), con la clasificación financiera, que divide el presupuesto en corriente y de capital, separando gastos de administración y de inversión; y dentro de estos últimos, precisando la inversión real, la inversión financiera y la transferencia de capital.

Sobre la base de este ordenamiento presupuestario, el control financiero puede operar con eficacia; mucho más si se considera que el presupuesto se ejecuta según un pro- 
grama anual de gastos, dividido en programas trimestrales, que a su vez, sirven de base para la dictación de los decretos de fơndos.

Luego, la clasificación por programas, u otra que la técnica aconseje, especialmente autorizada por la Ley Orgánica de Presupuestos, no afecta en absoluto la fiscalización financiera de la contraloría General, ya que se adoptaría además de la clasificación básica, y para fines diferentes.

Estos fines diferentes, como se ha expresado, estarían constituídos por la necesidad de armonizar los planes o programas del Estado con la gestión financiera y por la ventaja de efectuar un control por el resultado o rendimiento como fiscalización de la eficiencia orgánica de los Servicios Públicos.

Pero ambos objetivos, eminentemente valiosos, no corresponden en el régimen jurídico chileno a la Contraloría General, sino a la propia Administración Activa. En efecto, son los organismos ejecutivos de la Administración los encargados de verificar la forma en que se de cumplimiento a los planes o programas del Estado y la eficiencia orgánica de los Servicios Públicos, determinada por el resultado o rendimiento.

Para la fiscalización administrativo-jurídica del Organismo de Control es necesario poner énfasis en el ordenamiento administrativo del gasto, con glosas indicativas del destino de los fondos, a fin de confrontar la legalidad del egreso. En cambio, para el control de eficiencia es fundamental destacar el fin en función del gasto y el costo que supone el cumplimiento del objetivo, con el propósito de comprobar la medida en que el fin se cumple y el costo que representa.

Luego, resulta eficaz, la solución adoptada por la Ley Orgánica de Presupuestos, estableciendo una clasificación básica que facilita el control administrativo-jurídico, y una clasificación por programa, o en la forma que la técnica aconseje, para hacer posible el control de eficiencia. En estas condiciones, permite la existencia de dos clasificaciones, con distintos objetos, facilitando tanto el control administrativo-jurídico, que corresponde a la Contraloría General, como el control de eficiencia, que es propio de la Administración Activa.

\section{3.- El Control por el Resultado.}

Aunque en el régimen jurídico chileno el control de eficiencia escapa a la competencia de la Contraloría General, a la que sólo está reservado el control administrativojurídico, éste último resulta inoperante o incompleto sin la concurrencia de aquél.

Esto no significa que ambos deban ser concentrados en la misma entidad fiscalizadora, sino sólo importa que los dos controles se complementen y coordinen, sin perjuicio de que permanezcan separados.

Correspondiendo a la Administración Activa realizar los fines del Estado, parece propio mantener radicado en ella el control de eficiencia, reservando a la Contraloría General únicamente el control administrativo-jurídico, que actualmente ejerce.

Sin embargo, es imprescindible la debida coordinación y complementación de ambạs formas de fiscalizat ción, para cuyo efecto el Organis: 
mo de Control podría colaborar con la Administración Áctiva, en funciones de racionalización de la Administración Pública.

En el aspecto relativo a la coordinación y complementaciớn del control administrativo-jurídico y del control de eficiencia, basta señalar, para destacar la importancia que estas condiciones revisten, la ineficacia de un eficiente control administrativo-jurídico, que dé garantía absoluta de juridicidad y corrección en el empleo de los fondos, frente a Servicios Públicos técnicamente mal organizados, que derrochen esos recursos en bajos rendimientos.

En estas circunstancias coexistirían una corrección formal y una desorganización técnica, en condiciones tales que las deficiencias de la segunda, anularían con creces la eficacia de la primera.

Por consiguiente, es esencial que la Administración Activa adopte el presupuesto programa, o presupuesto funcional, y exija de los Servicios Públicos la elaboración de balances de costos, que permitan determinar el rendimiento o resultado del gasto, para apreciar la eficiencia orgánica de la entidad correspondiente.

Si bien el control por el resultado presenta dificultades en algunos servicios generales, como el de fiscalización de impuestos, constituidos en Chile por el Servicio de Impuestos Internos y la Superintendencia de Aduanas, el costo de recaudación de los tributos puede expresarse en un porcentaje de la suma recaudada, para determinar el rendimiento. A la vez, puede compararse con el costo de los distintos países, o fijarse técnicamente un costo racional, para determinar sobre su base la eficiencia orgánica del Servicio.

En otros casos, como en el de los Servicios de Educación, es apropiado, como medio de control por el rendimiento, el costo por alumnc en las diferentes ramas de la educación, y en las empresas estatales de transporte puede recurrirse al costo pasajero-kilómetro o tonelada-kilómetro, según proceda.

Sin duda, las empresas estatales facilitan notablemente el control por el resultado, por cuanto producen para un mercado con precios pre-existentes, que deben cubrir, normalmente; los costos de producción. Luego, en estos casos, incluso podría adoptarse el control por la rentabilidad, propio de la empresa privada, excepto cuando el Estado imponga precios inferiores al costo. por razones económicas y sociales.

$Y$ en las instituciones semifiscales, que ejercen sus funciones en Chile en el campo de la seguridad social, el control por el resultado podría apreciarse según la proporción en que los gastos de administración incidan en el monto global de los beneficios previsionales otorgados en el año presupuestario. Este porcentaje, igualmente, podría confrontarse entre las diversas instituciones previsionales y con los existentes en otros países, o determinarse técnicamente, a fin de precisar la eficiencia orgánica de entidad respectiva.

En general, el control por el resultado debe adaptarse a las condiciones propias y a los fines de cada Servicio Público. Constituye un control por el rendimiento, y se determina según el costo en relación con el resultado obtenido. Su aplica- 
ción misma supone una gran variedad de procedimientos y formas de medición, cuyo análisis integral excede el límite del tema tratado.

No obstante, es necesario destacar su importancia esencial, y la necesidad de una estrecha coordinación de este control con el de carácter administrativo-jurídico, ya que cualquiera de los dos, aisladamente, resulta ineficaz.

Para promover esta coordinación y complementación, considerando que ambas fiscalizaciones se ejercen separadamente, la Contraloría General debería estar representada en el Organismo de la Administración Activa encargado del control de eficiencia, por el resultado o rendimiento.

De esta manera, no sólo aportaría sus experiencias, especialmente adquiridas a través del control administrativo-jurídico, sino también, sobre la base de esa cooperación, podría introducir modalidades en el control referido, para adaptarlo a las exigencias del control de eficiencia.

En efecto, muchas veces las exigencias del control administrativojurídico, en cuanto suponen, trámites o actuaciones que entorpecen la gestión financiera de los Servicios Públicos, afectan la eficiencia de éstos, restan oportunidad a su acción o imponen costos adicionales.

Luego, muchas veces la racionalización orgánica, destinada a aumentar la eficiencia de los Servicios Públicos, va a exigir, conjuntamente, adaptaciones o modalidades en el control administrativo-jurídico, para cuyo efecto la cooperación de la Contraloría General y la Administración Activa, a través de un organismo integrado por ambas. parece de importancia fundamental.
En Chile, la implantación del control de eficiencia, por el resultado o rendimiento, ha tenido importancia relativa, mediante la creación de Oficinas de Organización y Método en los propios Servicios, Públicos o la contratación de entidades especializadas para la racionalización orgánica, pero no ha adquirido aún una expresión amplia y general.

Con tal objeto, debería crearse un organismo estatal permanente y dotado de amplias facultades, integrado a la Administración Activa; con representación de la Contraloría General, que asumiera la función de ejercer el control de eficiencia de todos los Servicios Públicos, centralizados o autónomos, y tuviera a su cargo la racionalización orgánica de aquéllos que, a través de ese control, acusaran deficiencias en el rendimiento o resultado.

\section{IV.- SINTESIS GENERAL :}

1) Considerando la trascendencia de los fines del Estado moderno, especialmente, su amplia acción económica y social, el sistema de control financiero debe adaptarse a las exigencias del fin, sin entorpecer o limitar su realización.

2) Coexistiendo los fines tradicionales del Estado, de carácter rutinario, con los objetivos económicos $\mathbf{y}$ sociales, incorporados a su acción, $\mathrm{y}$ con los fines puramente locales de las municipalidades, no puede adoptarse un solo régimen de administración financiera ni un solo sistema de control, sino diversos regímenes y sistemas, que armonicen con la naturaleza de los fines señalados.

3) En el plano de la administración financiera, en líneas generales, deben distinguirse tres sectores básicos: el sector fiscal centralizado, para los fines tradicionales, de ca- 
rácter rutinario; el sector fiscal descentralizado, para los fines económicos y sociales, que exigen iniciativas flexibles; y el sector municipal. para los fines locales.

4) En el sector fiscal centralizado, de acción rutinaria, la administración financiera puede ejercerse a través de una personalidad jurídica concentrada: la del Estado o Fisco, y por medio de un presupuesto único: el presupuesto fiscal, aprobado anualmente por ley. La rigidez del sistema, especialmente, la aprobación y modificación por ley del presupuesto anual, no afecta los fines tradicionales de este sector, susceptibles de previsión exacta, y basta el sistema de traspasos y el gasto de emergencia, dentro del régimen presupuestario, para ajustar las alteraciones que surjan en el curso de la gestión financiera.

5) En el sector fiscal descentralizado, de iniciativa flexible, se requiere una administración financiera ágil, que exige personalidad jurídica para cada ente autónomo, patrimonio propio y presupuesto aprobado por decreto supremo. La posibilidad de ejercer derechos y contraer obligaciones, directamente, y la mayour agilidad derivada de la aprobación y modificación del presupuesto por simple decreto, aseguran la suficiente flexibilidad a la gestión de este sector.

6) En el sector municipal, que sólo persigue fines de orden local, la autonomía financiera es necesaria parà la localización de la acción en el ámbito de la comuna y el ejercicio de las iniciativas que requiere la promoción y progreso comunales. Por consiguiente. la administración financiera requiere, para cada municipalidad, la existencia de personalidad jurídica propia, patrimonio separado $y$ presupuesto independiente del presupuesto fiscal. Siempre por razones regionales, la aprobación del presupuesto municipal, así como sus modificaciones, deben quedar sujetas a la resolución del Intendente de la Provincia a que esté integrada la respectiva comuna.

7) El Control finaciero de la Entidad Fiscalizadora debe adaptarse a las particulares características de administración de cada sector financiero, las que, a su vez, dependen de la naturaleza de los fines asignados.

8) En el sector fiscal centralizado. en general, el control financiero debe ejercerse, en forma previa, en eI trámite de toma de razón de decretos periódicos de fondos que, impu. tando el gasto al ítem respectivo de la ley anual de presupuesto, determinen los fines a que se destinarán los recursos. Con los fondos imputados y para los fines previstos. los Servicios Públicos deben ejecutar los gastos sin necesidad de resolu ción, y rendir cuenta al término del período respectivo.

9) En el sector fiscal descentralizado, en general, el control financicro debe ejercerse, en forma previa, en el acto de toma de razón de los decretos supremos que aprueben los presupuestos de los entes autớnomos, y en el trámite de toma de razón de las resoluciones de fondos que, en forma períodica, dicten de los Jefes de Servicios, imputando el gasto y señalando el fin. Sobre la base de esas resoluciones, se efer:túan los gastos en la forma prevista. y se rinde cuenta al final del período. El control se refuerza mediante la acción de auditores destacados en forma permanente, durante el curso del ejercicio presupuestario; $y$ al 
término de éste, se confronta la previsión con la ejecución, mediante un balance final, presentado por la entidad correspondiente.

10) En el sector municipal, en general, el control financiero debe ejecerse, en forma previa, por medio del trámite de toma de razón de la resolución del Intendente de la respectiva provincia, que aprueba ei presupuesto municipal. Al término del ejercicio, mediante un balance final de cada municipalidad, en que se confronte la previsión con la ejecución. Y durante su curso, mediante rendiciones de cuentas periódicas y visitas de Inspectores. designados para este efecto.

11) Tanto en el sector fiscal des. centralizado como en el sector municipal, en previsión de los atrasos que pudieran surgir en la tramitación de los presupuesiós, debería contemplarse un procedimiento de emergencia, que permitiera, previa autorización, gastar sin el presupuesto aprobado, por duodécimos, en los primeros meses del año correspondiente.

12) Chile ha acogido la Recomendación III. 2, del Tercer Congreso de Entidades Fiscalizadoras, celebrado en Río de Janeiro, Brasil, contemplando en su Ley Orgánica de Presupuestos una clasificación de gastos, de carácter básico, que combina el ordenamiento administrativo con el ordenamiento en función del fin. Además, ha previsto y autorizado, conjuntamente con esta cla- sificación básica, otra en relación con programas, o en la forma que la técnica aconseje, lo que permitiría poner énfasis en el fin $u$ objeto del gasto, y determinar el costo de su realización, para facilitar el control de eficiencia, por el rendimiento o resultado.

13) Aunque al Organismo de Control, en el régimen jurídico chileno, sólo corresponde la fiscalización administrativo-jurídica, es esencial completar este control con la fiscalización de eficiencia, por el rendimiento o resultado, radicada en el ámbito de las funciones de la Administración Activa.

14) El control de eficiencia por el rendimiento o resultado, apreciado según el costo, y en las empresas estatales, cuando proceda, por la rentabilidad, debería servir de base para la racionalización de los Servicios Públicos que acusen deficiencias orgánicas por su bajo rendimiento.

15) Las Entidades Fiscalizadoras si bien no tienen a su cargo el control de eficiencia, radicado en la Administración Activa, deberían coope. rar en su ejercicio, a fin de que, tanto el control administrativo-jurídico como el de eficiencia, aparezcan complementados y coordinados. Para este efecto, en los organismos creados con el objeto de ejercer el control de eficiencia, las entidades fiscalizadoras deberian estar representadas.

Santiago, Marzo de 1965. 